\title{
PENGARUH PELAKSANAAN KEBIJAKAN DANA DESA TERHADAP KESEJAHTERAAN MASYARAKAT MELALUI PEMBERDAYAAN MASYARAKAT: STUDI KASUS DI KECAMATAN SIANTAR NARUMONDA KABUPATEN TOBA
}

\author{
Nalom Siagian ${ }^{1}$ Darma Manalu ${ }^{2}$ Artha Lumban Tobing ${ }^{3}$
}

Article history:

Submitted:

10 September 2020

Revised:

30 Maret 2021

Accepted:

31 Maret 2021

\section{Keywords:}

Rural fund Policy;

Community Empowerment;

Community Welfare.

\section{Kata Kunci:}

Kebijakan Dana Desa;

Pemberdayaan Masyarakat;

Kesejahteraan Masyarakat.

\section{Koresponding:}

Fakultas Ilmu Sosial dan Politik Universitas HKBP Nommensen Medan, Sumatera Utara, Indonesia

Email:

nalomsiagian.uhn@gmail.com

\section{Abstract}

The purpose of this study was to analyze the effect of implementing rural fund policies and community empowerment on community welfare. This research was conducted in 14 (fourteen) villages scattered in Siantar Narumonda District, Toba Regency. The number of respondents in this study were 220 people who were taken using the proportional random sampling method. The data collected in this study were analyzed using structural equation model. Based on the results of the analysis, concluded that directly, the implementation of the rural fund policy has a significant positive effect on community empowerment. The implementation of the rural fund policy has a negative and insignificant effect on community welfare, while community empowerment has a significant positive effect on community welfare. Indirectly, the implementation of the rural fund policy has a significant positive effect on community welfare through community empowerment.

\section{Abstrak}

Tujuan dari penelitian ini adalah untuk menganalisis pengaruh pelaksanaan kebijakan dana desa dan pemberdayaan masyarakat terhadap kesejahteraan masyarakat. Penelitian ini dilakukan pada 14 (empat belas) Desa yang tersebar di Kecamatan Siantar Narumonda Kabupaten Toba. Jumlah responden dalam penelitian ini sebanyak 220 masyarakat yang diambil dengan menggunakan metode proportional random sampling. Data yang terkumpul dalam penelitian ini dianalisis dengan menggunakan analisis strucutre equation model. Berdasarkan hasil analisis yang dilakukan, disimpulkan bahwa secara langsung pelaksanaan kebijakan dana desa berpengaruh positif signifikan terhadap pemberdayaan masyarakat. Pelaksanaan kebijakan dana desa berpengaruh negatif tidak signifikan terhadap kesejahateraan masyarakat, sedangkan pemberdayaan masyarakat berpengaruh positif signifikan terhadap kesejahteraan masyarakat. Secara tidak langsung, pelaksanaan kebijakan dana desa berpengaruh positif signifikan terhadap kesejahteraan masyarakat melalui pemberdayaan masyarakat.

Fakultas Ilmu Sosial dan Politik Universitas HKBP Nommensen Medan, Sumatera Utara, Indonesia ${ }^{2,3}$ 


\section{PENDAHULUAN}

Komoditas Pada hakekatnya, pembangunan suatu Negara bertujuan untuk meningkatkan kesejahteraan dan memberikan kemakmuran yang sebesar-besarnya bagi masyarakatnya, dengan memenuhi kebutuhannya agar dapat hidup layak dan mampu mengembangkan diri dalam melaksanakan fungsi sosialnya. Badan Pusat Statistik (2016) menyebutkan indikator kesejahteraan masyarakat meliputi: penghasilan, konsumsi, tempat tinggal, kesehatan masyarakat, akses layanan kesehatan, pendidikan dan kemudahan akses transportasi.

Arsyad (2010) menjelaskan untuk mewujudkan masyarakat yang sejahtera dibutuhkan serangkaian usaha dan kebijakan pemerintah, mulai dari pemerintah pusat, pemerintah propinsi, kabupaten/kota hingga pemerintah desa semuanyanya bertanggung jawab mensejahterakan masyarakatnya. Undang-Undang Nomor 6 Tahun 2014 menjelaskan bahwa pada prinsipnya, Desa merupakan entitas masyarakat dalam suatu wilayah tertentu yang memiliki kewenangan untuk mengatur dan mengurusi kesejahteraan masyarakat berdasarkan prakarsa masyarakat, hak asal usul, dan/atau hak tradisional yang diakui sistem pemerintahan Indonesia. Sebagai bentuk dukungan atas pelaksanaan tugas dan fungsi desa dalam penyelenggaraan pemerintahan dan pembangunan dalam segala aspek kewenangannya, maka dana desa harus dikelola dengan manajemen yang akuntabel dan dilaksanakan dengan kebijakan yang baik melalui program, aktifitas, aksi, atau tindakan dalam suatu mekanisme yang terikat pada suatu sistem tertentu (Ramadhani \& Ramadhani, 2017). Melalui pelaksanaan kebijakan dana desa, peran pemerintah desa ditingkatkan dalam memberikan pelayanan kepada masyarakat untuk tujuan peningkatan kesejahteraan masyarakat.

Nugroho (2014) menyebutkan 4 (empat) dimensi dalam melaksanakan kebijakan dana desa, yaitu komunikasi, sumber daya, disposisi dan struktur organisasi. Subarsono (2005) menyebutkan terdapat 5 (lima) dimensi implemantasi kebijakan, yaitu : Standar dan sasaran kebijakan, Sumberdaya, Komunikasi antar organisasi dan penguatan aktivitas, Karakteristik agen pelaksana serta Kondisikondisi sosial, ekonomi, dan politik.

Pasal 1 ayat 2 Peraturan Pemerintah Nomor 60 Tahun 2014 dan Pasal 2 ayat 1 Peraturan Menteri Dalam Negeri No 113 Tahun 2014 yang menginstruksikan agar dana desa digunakan membiayai penyelenggaraan pemerintahan, pelaksanaan pembangunan, pembinaan kemasyarakatan dan pemberdayaan masyarakat untuk tujuan peningkatan kesejahteraan masyarakat dengan melibatkan lembaga kemasyarakatan. Ife \& Tesoriero (2008) menyebutkan terdapat 6 (enam) dimensi dalam pemberdayaan masyarakat, yaitu: Pengembangan sosial, Pengembangan ekonomi, Pengembangan politik, Pengembangan budaya, Pengembangan lingkungan dan Pengembangan personal/ spiritual.

Dengan demikian, dapat dipahami bahwa berbicara tentang pelaksanaan kebijakan dana desa erat kaitannya dengan pemberdayaan masyarakat dan kesejahteraan masyarakat, walaupun dalam 
implementasinya rentan dengan intervensi dan kepentingan pragmatis yang berujung pada tidak tercapainya penyerapan anggaran yang optimal. Fenomena ini hampir terjadi di kebanyakan pelaksanaan kebijakan dana desa di Indonesia, termasuk di Kecamatan Siantar Narumonda Kabupaten Toba.

Alokasi anggaran dana desa di Kecamatan Siantar Narumonda Kabupaten Toba pada Tabel 1. menunjukkan masih jauh dari angka penyerapan anggaran $100 \%$. Total anggaran dana desa yang disediakan Pemerintah untuk seluruh Desa di Kecamatan Siantar Narumonda sebesar Rp. 9.114.378.000,- pada tahun 2018 hanya terserap sebesar $35,34 \%$ dengan besaran alokasi Rp. 3.220.902.000,-. Penyerapan anggaran dana desa tertinggi diserap Desa Siantar Tonga-tonga I, yaitu sebesar 36,03\%, dengan jumlah dana desa teralokasi sebesar Rp. 231.471.000,- dari anggaran dana desa sebesar Rp. 646.285.000,- dan penyerapan anggaran dana desa terendah diserap Desa Narumonda V, yaitu sebesar $34,32 \%$, dengan jumlah dana desa teralokasi sebesar Rp. 233.673.000,- dari anggaran dana desa sebesar Rp. 680.873.000. Kemampuan penyerapan anggaran dana desa di Kecamatan Siantar Narumonda masih sangat rendah dan jauh dari dari yang diharapkan.

Observasi lebih lanjut yang dilakukan menunjukan pelaksanaan kebijakan dana desa yang meliputi perencanaan, pelaksanaan, dan pengendalian kegiatan belum memberdayakan masyarakat seutuhnya dalam musyawarah penggunaannya dan lebih banyak diintervensi oleh Kepala Desa, sehingga pembangunan desa di Kecamatan Siantar Narumonda Kabupaten Toba kurang menyentuh substansi peningkatan kesejahteraan masyarakat. Akses masyarakat terhadap layanan kesehatan masih sangat terbatas.

Tabel 1.

Penyerapan Anggaran Dana Desa di Kecamatan Siantar Narumonda Tahun 2018 (Dalam Rp. 000)

\begin{tabular}{ccccc}
\hline No. & Desa & Alokasi Dana Desa & $\begin{array}{c}\text { Anggaran Dana } \\
\text { Desa }\end{array}$ & $\begin{array}{c}\text { Penyerapan Anggaran } \\
(\%)\end{array}$ \\
\hline 1 & Narumonda V & 233.673 & 680.873 & 34,32 \\
2 & Narumonda VI & 232.108 & 648.538 & 35,79 \\
3 & Narumonda VII & 230.050 & 667.731 & 34,45 \\
4 & Narumonda VIII & 227.108 & 639.281 & 35,53 \\
5 & Siantar Sitio-tio & 227.703 & 649.016 & 35,08 \\
6 & Narumonda I & 233.738 & 665.778 & 35,11 \\
7 & Narumonda II & 225.305 & 635.786 & 35,44 \\
8 & Narumonda III & 230.973 & 647.007 & 34,56 \\
9 & Narumonda IV & 229.687 & 664.682 & 35,87 \\
10 & Siantar Tonga-tonga II & 229.966 & 641.023 & 35,24 \\
11 & Siantar Dangsina & 229.246 & 650.618 & 35,82 \\
12 & Siantar Tonga-tonga I & 231.471 & 646.285 & 36,03 \\
13 & Siantar Sigordang & 230.982 & 641.068 & 35,95 \\
14 & Siantar Tonga-tonga III & 228.892 & 636.692 & 35,34 \\
\hline
\end{tabular}

Sumber : Badan Pusat Statistik Kecamatan Siantar Narumonda (2019) 
Badan Pusat Statistik Kecamatan Siantar Narumonda (2019) mencatat hanya 1 (satu) Puskesmas, 2 (dua) belas Poskesdes dan 14 (empat belas) Posyandu. Demikian halnya dengan akses masyarakat untuk mendapatkan fasilitas pendidikan juga sangat terbatas, karena minimnya fasilitas sekolah. Bahkan banyak desa di Kecamatan Siantar Narumonda yang tidak memiliki fasilitas sekolah, baik SD/MI, SMP/MTs, terlebih SMA/MA sederjat. Badan Pusat Statistik Kecamatan Siantar Narumonda (2019) mencatat hanya ada 1 (satu) SMA/MA sederajat, 3 (tiga) SMP/MTs Sederajat dan 8 (delapan) SD/MI sederajat di Kecamatan Siantar Narumonda.

Fenomana praktis ini menambah daftar panjang perdebatan hubungan pelaksanaan kebijakan dana desa dengan pemberdayaan masyarakat dan kesjahteraan masyarakat. Fathony \& Sopian (2019); Oleh (2014) dalam penelitiannya membuktikan terdapat pengaruh pelaksanaan kebijakan dana desa yang positif dan signifikan, baik terhadap pemberdayaan masyarakat maupun terhadap kesejahteraan masyarakat. Mahendra (2017) dalam penelitiannya menemukan pemberdayaan masyarakat Program PNPM Mandiri Perkotaan bidang infrastruktur berpengaruh positif terhadap Kesejahteraan Masyarakat PNPM Mandiri Perdesaan di Kecamatan Denpasar Utara. Berbeda dengan Nurohman dkk., (2019) yang justeru menemukan alokasi dana desa berpengaruh negatif terhadap kesejahhteraan. Maulana (2017) dalam penelitiannya membuktikan pengelolaan alokasi dana desa tidak berjalan lancar dalam meningkatkan pemberdayaan masyarakat.
Berdasarkan telaah dan kajian penelitian terdahulu, maka penelitian ini dilakukan kembali dengan tujuan : 1) Untuk menganalisis sekaligus mengetahui pengaruh langsung pelaksanaan kebijakan dana desa terhadap kesejahteraan masyarakat pedesaan. 2) Untuk menganalisis sekaligus mengetahui pengaruh langsung pemberdayaan masyarakat terhadap kesejahteraan masyarakat pedesaan. 3) Untuk menganalisis sekaligus mengetahui pengaruh langsung pelaksanaan kebijakan dana desa terhadap pemberdayaan masyarakat pedesaan. 4) Untuk menganalisis sekaligus mengetahui pengaruh pelaksanaan kebijakan dana desa terhadap kesejahteraan masyarakat pedesaan melalui pemberdayaan masyrakat.

Hipotesis dalam penelitian ini disusun sebagai berikut :

H1. Pelaksanaan kebijakan dana desa berpengaruh positif dan signifikan terhadap kesejahteraan masyarakat pedesaan.

H2. Pemberdayaan masyarakat berpengaruh positif dan signifikan terhadap kesejahteraan masyarakat pedesaan.

H3. Pelaksanaan kebijakan dana desa berpengaruh positif dan signifikan terhadap pemberdayaan masyarakat pedesaan.

H4. Pelaksanaan kebijakan dana desa berpengaruh positif dan signifikan terhadap kesejahteraan masyarakat pedesaan melalui pemberdayaan masyarakat

\section{METODE PENELITIAN}

Desain penelitian atau jenis penelitian yang digunakan dalam penelitian ini adalah penelitian kuantitatif, yaitu metode penelitian yang berlandaskan pada filsafat positivisme, 
digunakan untuk meneliti pada populasi atau sampel tertentu, teknik sampling dilakukan secara random, data dikumpulkan melalui instrumen penelitian, dan data dianalisis secara kuantitatif/statistik untuk menguji hipotesis yang diteliti (Sugiyono, 2007). Penelitian ini dilakukan di seluruh Desa yang tersebar di Kecamatan Siantar Narumonda Kabupaten Toba yang berjumlah 14 (empat belas) Desa. Ditetapkannya keempat belas Desa se Kecamatan Siantar Narumonda menjadi lokasi penelitian ini untuk merepresentasi permasalahan kebijakan dana desa, pemberdayaan dan kesejahteraan masyarakat. Penelitian ini dilakukan dalam kurun waktu 6 (enam) bulan terhitung sejak bulan Maret 2020 hingga September 2020.

Populasi penelitian ini masyrakat yang tersebar di seluruh Desa se-Kecamatan Siantar Narumonda sebanyak 6.032 jiwa. Mengingat jumlah populasi dalam penelitian ini sangat besar $(>100)$, maka tidak memungkinkan dilakukan penelitian populasi, melainkan mengambil beberapa sampel yang representatif. Jumlah sampel dalam penelitian ini dihtiung dengan menggunakan rumus Slovin dalam Noor (2011) :

$$
n=\frac{N}{1+N \cdot e^{2}}
$$

Keterangan :

$\mathrm{n} \quad=\quad$ Ukuran sampel

$\mathrm{N}=$ Ukuran populasi

e $\quad=$ Kelonggaran ketidaktelitian karena kesalahan pengambilan sampel yang dapat ditolerir, kemudian dikuadratkan.

Dengan tingkat kelonggaran ketelitian $5 \%$, didapat jumlah sampel dalam penelitian ini sebanyak 244,96 jiwa atau dibulatkan menjadi 245 jiwa. Sampel dalam penelitian ini diambil secara acak, sehingga setiap populasi memiliki kesempatan sama menjadi sampel penelitian. Pengumpulan data dalam penelitian ini selanjutnya dilakukan dengan menggunakan kuesioner dengan pengukuran skala likert.

Variabel bebas dalam penelitian ini adalah pelaksanaan kebijakan dana desa, variabel interveningnya adalah pemberdayaan masyrakat dan variabel terikatnya kesejahteraan masyarakat. Secara operasional, variabel pelaksanaan kebijakan dana desa dalam penelitian ini didefinisikan sebagai tindakan yang dilakukan individu maupun kelompok yang ditujukan untuk mencapai tujuan yang telah ditetapkan dalam keputusan kebijakan pengalokasian dana desa. Adapun tindakan dimaksud meliputi : standar dan sasaran kebijakan, sumberdaya, komunikasi antar organisasi dan penguatan aktivitas, karakteristik agen pelaksana serta kondisikondisi sosial, ekonomi, dan politik.

Pemberdayaan masyarakat adalah kegiatan pengembangan masyarakat dalam mewujudkan kemampuan dan kemandirian dalam kehidupan bermasyarakat. Adapun kegiatan pengembangan dimaksud, antara lain : pengembangan sosial, pengembangan ekonomi pengembangan politik, pengembangan budaya pengembangan lingkungan dan pengembangan personal.

Kesejahteraan masyarakat dimaksud dimaksud dalam penelitian, secara operasional didefinisikan sebagai kondisi terpenuhinya kebutuhan masyrarakat agar dapat hidup layak dan mampu mengembangkan diri, sehingga dapat melaksanakan fungsi sosialnya. Kondisi 
dimaksud, meliputi : pendapatan, konsumsi atau pengeluaran keluarga, keadaan tempat tinggal, fasilitas tempat tinggal, kesehatan anggota keluarga, kemudahan mendapatkan pelayanan kesehatan, kemudahan memasukkan anak kejenjang pendidikan, dan kemudahan mendapatkan fasilitas transportasi.

Data dalam penelitian ini dianalisis dengan menggunakan pendekatan analsisi SEM (structure equation model)/model persamaan berstruktur dengan program AMOS 22. Menurut Waluyo (2011), penggunaan analisis SEM sangat memungkinkan digunakan untuk pengujian sebuah rangkaian hubungan yang relatif rumit secara simultan. Secara matematis struktur persamaan dalam penelitian ini diformulasikan sebagai berikut :

Struktur Persamaan Langsung :

$X_{2}=\beta_{1} X_{1}+\mathrm{em}_{1}$

$Y=\beta_{2} X_{1}+\beta_{3} X_{2}+\mathrm{em}_{2}$

Struktur Persamaan Tidak Langsung

$\mathrm{Y}=\left|\beta_{1}+\beta_{3}\right| \mathrm{X}_{1}+\mathrm{em}_{1}$

Keterangan :

$\mathrm{Y} \quad=$ Kesejahteraan Masyarakat

$\mathrm{X}_{1} \quad=$ Pelaksanaan Kebijakan Dana Desa

$\mathrm{X}_{2} \quad=$ Pemberdayaan Masyarakat

$\beta_{1}=$ Koefesien Regresi Jalur Langsung $\mathrm{X}_{1} \rightarrow \mathrm{Y}$

$\beta_{2} \quad=$ Koefesien Regresi Jalur Langsung $\mathrm{X}_{2} \rightarrow \mathrm{Y}$

$\beta_{3}=$ Koefesien Regresi Jalur Langsung $\mathrm{X}_{1} \rightarrow \mathrm{X}_{2}$ $\mathrm{em}_{1}=$ error of model pengaruh pelaksanaan kebijakan dana desa terhadap pemberdayaan masyarakat

$\mathrm{em}_{2}=$ error of model pengaruh pelaksanaan kebijakan dana desa dan terhadap pemberdayaan masyarakat terhadap kesejahteraan masyarakat.

\section{HASIL DAN PEMBAHASAN}

Data penelitian diperoleh dari hasil kuesioner yang disebarkan kepada responden penelitian. Dari 245 kuesioner yang disebarkan kepada responden, sebanyak 220 kuesioner berhasil dikumpulkan kembali, sedangkan sisanya sebanyak 25 kuesioner lagi dinyatakan gugur, karena hingga batas waktu yang ditentukan, responden tidak kunjung mengembalikan kuesioner kepada peneliti.

Hasil uji validitas dan reliabilitas kuesioner yang berhasil dikumpulkan dalam penelitian ini dirangkum dalam pada Tabel 2 . Uji validitas dan reliabilias yang dlakukan dalam penelitian ini menghasilkan nilai loading factor dan AVE dari masing masing indikator yang digunakan untuk menjelaskan variabel konstruk dalam penelitian $>0.7$ dan nilai Composite reliability $(\mathrm{CR}) \geq 0,7$. Nilai faktor loading antara 0,5-0,6 maka dikatakan cukup valid dan nilai faktor loading $\geq 0,7$ dikatakan tinggi (Ghozali, 2011). Menurut Yamin dan Kurniawan (2011), nilai average variance extracted (AVE) minimal 0,5 menunjukkan ukuran Convergent Validity yang baik.. Kriteria dikatakan realibel adalah nilai $\mathrm{CR} \geq$ 0,7. Dengan demikian dapat disimpulkan 
seluruh instrumen kuesioner dalam penelitian ini dinyatakan valid dan reliabel.

Tabel 2.

Hasil Uji Validitas dan Reliabilitas

\begin{tabular}{|c|c|c|c|c|}
\hline Konstruk & Indikator & $\begin{array}{l}\text { Loading } \\
\text { Factor }\end{array}$ & AVE & CR \\
\hline \multirow{6}{*}{$\begin{array}{l}\text { Kebijakan } \\
\text { Pelaksanaan } \\
\text { Anggaran } \\
\text { Dana Desa }\end{array}$} & ADD1 & 0,786 & \multirow[t]{6}{*}{0,707} & \multirow[t]{6}{*}{0,741} \\
\hline & ADD2 & 0,911 & & \\
\hline & ADD3 & 0,799 & & \\
\hline & ADD4 & 0,964 & & \\
\hline & ADD5 & 0,802 & & \\
\hline & ADD6 & 0,762 & & \\
\hline \multirow{6}{*}{$\begin{array}{l}\text { Pemberdayaan } \\
\text { Masyarakat }\end{array}$} & PM1 & 0,714 & \multirow[t]{6}{*}{0,730} & \multirow[t]{6}{*}{0,758} \\
\hline & PM2 & 0,958 & & \\
\hline & PM3 & 0,730 & & \\
\hline & PM4 & 0,942 & & \\
\hline & PM5 & 0,781 & & \\
\hline & PM6 & 0,959 & & \\
\hline \multirow{8}{*}{$\begin{array}{l}\text { Kesejahteraan } \\
\text { Masyarakat }\end{array}$} & KM1 & 0,795 & \multirow[t]{8}{*}{0,714} & \multirow[t]{8}{*}{0,746} \\
\hline & KM2 & 0,789 & & \\
\hline & KM3 & 0,948 & & \\
\hline & KM4 & 0,751 & & \\
\hline & KM5 & 0,762 & & \\
\hline & KM6 & 0,953 & & \\
\hline & KM7 & 0,752 & & \\
\hline & KM8 & 0,970 & & \\
\hline
\end{tabular}

Sumber: Data diolah, 2020

Hair et al., (1995) menyebutkan terdapat asumsi-asumsi data yang harus dipenuhi ketika melakukan analisis SEM, diantaranya uji kecukupan sampel, normalitas dan outliers. Ukuran sampel minimum yang diperlukan untuk mengurangi bias pada semua jenis estimasi Structural Equation Modeling (SEM) adalah 200 (Loehlin, 1998). Jumlah sampel yang digunakan dalam penelitian ini berjumlah 245 responden. Berdasarkan hal tersebut dapat disimpulkan jumlah sampel dalam penelitian ini melampuai ambang batas kecukupan sampel minimum analisis SEM. Berikutnya Data yang akan diuji dengan metode SEM harus memenuhi asumsi normalitas data atau data berdistribusi secara normal. Hair et al., (1995) menyebutkan suatu data dikatakan berdistribusi normal apabila nilai critical ratio (C.R.) skewness tidak melebihi $+2,58$ pada taraf signifikan 5\%. Hasil pengolahan data menemukan bahwa nilai Critical ratio yang dihasilkan lebih kecil dari $+2,58$ pada tingkat signifikasi 5\%. Ini artinya bahwa seluruh data yang digunakan dalam penelitian ini terbebas dari asumsi normalitas, atau data yang digunakan berdisitribusi secara normal. Ferdinand (2006) mengatakan Data yang akan diuji dengan metode SEM tidak boleh mengandung outlier atau data yang bersifat ekstrem. Evaluasi outlier dapat dilakukan dengan mengunakan outlier multivariate, yaitu dengan cara mengidentifikasi nilai PValue dari jarak mahalonobis (mahalonobis distance) yang harus $\leq 0,001$. Hasil pengolahan data yang dilakukan menunjukkan nilai P-Value dari jarak mahalonobis (mahalonobis distance) $\leq 0,001$. Dapat disimpulkan bahwa data yang terkumpul dalam penelitian ini tidak mengandung outlier atau data yang bersifat ekstrim. Hasil evaluasi keseluruhan asumsi SEM yang dilakukan dalam penelitian ini menunjukkan bahwa asumsi-asumsi data telah terpenuhi untuk dilakukan analisis SEM.

Hasil analisis SEM dalam penelitian ini ditunjukkan pada Gambar 1. Secara matematis diformulasikan model persamaan berstruktur dalam penelitian ini sebagai berikut:

Struktur Persamaan Langsung

$\mathrm{X}_{2}=0,52 \mathrm{X}_{1}+\mathrm{em}_{1}$

$Y=-0,13 X_{1}+0,96 X_{2}+\mathrm{em}_{2}$

Struktur Persamaan Tidak Langsung

$\mathrm{Y}=(0,52 * 0,96) \mathrm{X}_{1}+\mathrm{em}_{2}$.

$\mathrm{Y}=0,499 \mathrm{X}_{1}+\mathrm{em}_{2}$ 


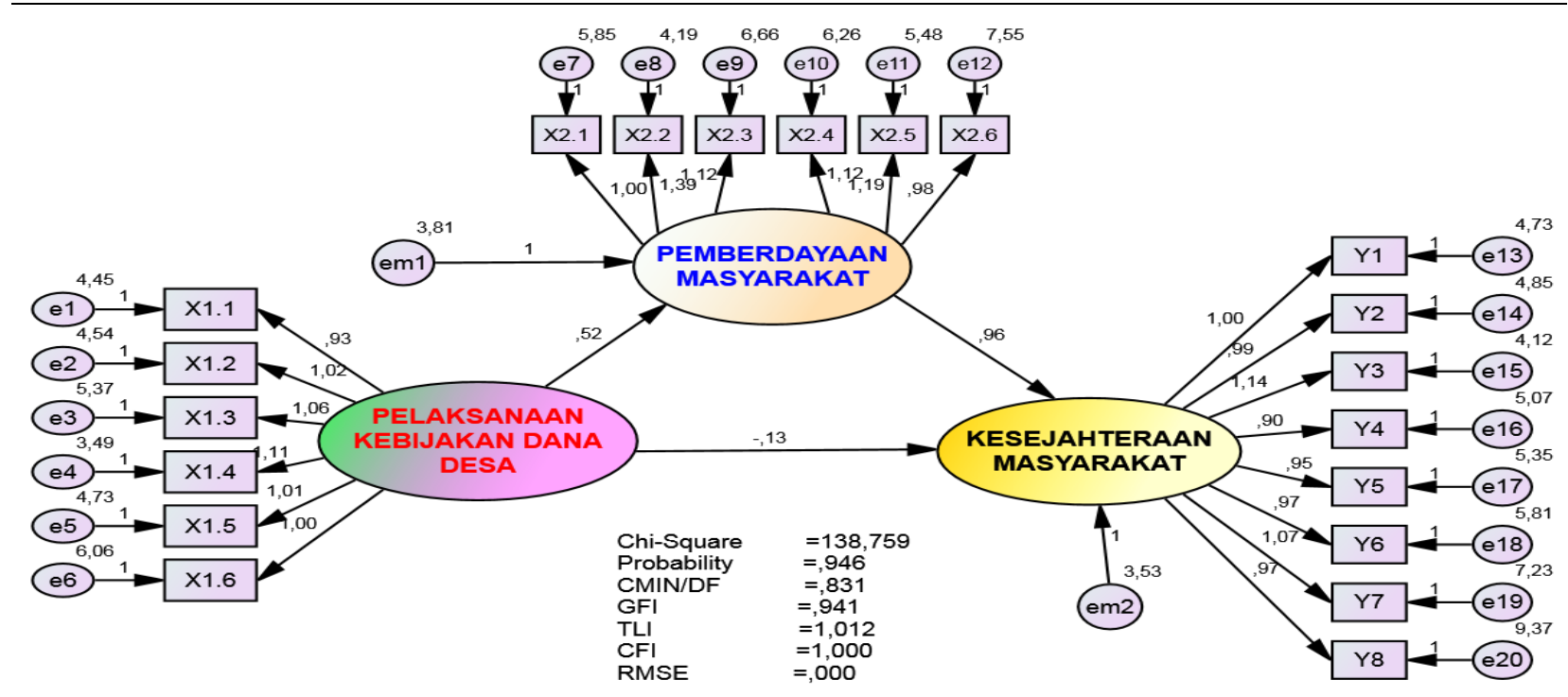

Gambar 1.

Hasil Analisis SEM Pengaruh Pelaksanaan Kebijakan Dana Desa terhadap Kesejahteraan Masyarakat melalui Pemberdayaan masyarakat

Pelaksanaan kebijakan dana desa $\left(\mathrm{X}_{1}\right)$ berpengaruh positif sebesar 0,52 terhadap pemberdayaan masyarakat $\left(\mathrm{X}_{2}\right)$. Pelaksanaan kebijakan dana desa diestimasi dapat meningkatkan pemberdayaan masyarakat sebesar 0,52. Pelaksanaan kebijakan dana desa $\left(\mathrm{X}_{1}\right)$ berpengaruh negatif sebesar $-0,13$ terhadap kesejahteraan masyarakat (Y). Pelaksanaan kebijakan dana desa diestimasi menurunkan kesejahteraan masyarakat sebesar 0,13 . Pemberdayaan masyarakat $\left(\mathrm{X}_{2}\right)$ berpengaruh positif sebesar 0,96 terhadap kesejahteraan masyarakat (Y). Pemberdayaan masyarakat diestimasi dapat meningkatkan kesejahteraan masyarakat sebesar 0.96 .

Pelaksanaan kebijakan dana desa berpegaruh positif sebesar 0,499 terhadap kesejahteraan masyarakat melalui pemberdayaan masyarakat. Pelaksanaan kebijakan dana desa diestimasi dapat meningkatkan kesejahteraan masyarakat sebesar 0,499 melalui pemberdayaan masyarakat.
Hasil uji kelayakan (goodnes of fit tes) model persamaan berstruktur yang dihasilkan dalam penelitian ini dirangkum dalam Tabel 3.

Tabel 3.

Goodness of Fit Test

\begin{tabular}{lccc}
\hline $\begin{array}{c}\text { Goodness } \text { Of } \\
\text { Fit Index }\end{array}$ & $\begin{array}{c}\text { Cut-off } \\
\text { Value }\end{array}$ & $\begin{array}{c}\text { Hasil } \\
\text { model }\end{array}$ & Kriteria \\
\hline $\begin{array}{l}\text { Chi-Square } \\
\text { n220 df167 }\end{array}$ & $\leq 198,154$ & 139,759 & Layak \\
$\alpha 5 \%$ & & & \\
\hline Probabilitas & $\geq 0.05$ & 0,946 & Layak \\
\hline CMIN/DF & $\leq 2.00$ & 0,831 & Layak \\
\hline GFI & $\geq 0.90$ & 0,941 & Layak \\
\hline TLI & $\geq 0.95$ & 1,012 & Layak \\
\hline CFI & $\geq 0.95$ & 1,000 & Layak \\
\hline RMSEA & $\leq 0.08$ & 0,000 & Layak \\
\hline
\end{tabular}

Sumber : Data Diolah, 2020

Ferdinand (2006) menyebutkan model dipandang layak untuk diimplementasikan bila memiliki nilai Chi-square nya rendah dan probability $>0,05$. CMIN/DF $\leq 2.0$, GFI (Goodness of Fit Index) $\geq 0,90$, TLI (Tucker Lewis Index) $\geq 0,95$, CFI (Comparative Fit 
Index) $\geq 0,94$, RMSEA yang lebih kecil atau sama dengan 0,08 .

Pengolahan data sebagaimana dirangkum dalam Tabel 3 menunjukkan nilai Chi-Square ketiga struktur model estimasi yang dihasilkan dalam penelitian ini sebesar 139,759, lebih kecil dari koefisien cutoff value Chi-Square n220 df167 $\alpha 5 \%=$ 198,154, Probability sebesar 0,946 lebih besar dari koefisien cutoff-nya sebesar 0,05, CMIN/DF sebesar 0,831 lebih kecil dari koefisien cutoff-nya 2,00, GFI sebesar 0,941 lebih besar dari koefisien cutoff-nya sebesar 0,90, TLI 1,012 > dari koefisien cutoff-nya 0,95, CFI 1,000 > dari koefisien cutoff-nya sebesar 0.95 dan RMSEA sebesar 0,000 lebih kecil dari koefisien cutoff-nya sebesar 0.08. Dapat disimpulkan bahwa model persamaan berstruktur yang dihasilkan dalam penelitian ini layak untuk diimplementasikan.

Hipotesis yang dirumuskan dalam penelitian ini dikelompokkan kedalam 2 (dua) kelompok hipotesis, yaitu Kelompok 1, Hipotesis $1(\mathrm{H} 1)$ dan (H2) merupakan direct effect hypothesis. Hipotesis 1 (H1) dan (H2) dalam penelitian ini diuji dengan menggunakan indikator $C R$ of Regression Weights: (Group number 1 - Default model) pada output AMOS, atau yang dipersamakan dengan indikator $\mathrm{t}$ yang lazim digunakan dalam model-model regresi. Kelompok 2, Hipotesis 3 (H3) merupakan inderect efect hypothesis, nilai t-nya dihitung dengan menggunakan Sobel Test.Penerimaan atau penolakan hipotesis ditentukan dengan ketentuan: Terima Ho atau Tolak Ha, jika nilai $\mathrm{t} / \mathrm{CR}_{\text {hitung }}<$ dari nilai $\mathrm{t} / \mathrm{CR}_{\text {tbael }} \mathrm{DF}(\mathrm{n}-\mathrm{k})$ $\alpha 5 \%$ atau nilai probability-nya $>$ dari $\alpha 5 \%$, dan sebaliknya, Terima Ha dan Tolak Ho, jika nilai $\mathrm{t} / \mathrm{CR}_{\text {hitung }}>$ dari nilai $\mathrm{t} / \mathrm{CR}_{\text {tbael }} \mathrm{DF}(\mathrm{n}$ k) $\alpha 5 \%$ atau nilai probability-nya $>\alpha 5 \%$ (Ghozali, 2011).

Hasil pengujian hipotesis dalam penelitian ini ditunjukkan pada Tabel 4.

Tabel 4.

Hasil Pengujian Hipotesis

\begin{tabular}{|c|c|c|c|c|c|c|}
\hline \multicolumn{2}{|c|}{ Variabel Penelitian } & \multicolumn{3}{|c|}{ Direct Effect } & \multicolumn{2}{|c|}{ Inderect Efect } \\
\hline Terikat & Bebas & $\begin{array}{l}\text { Koef. } \\
\text { Est. }\end{array}$ & $\begin{array}{l}\text { CR } \\
\text { (Prob) }\end{array}$ & Kriteria & $\begin{array}{ll}\text { Koef. } & \text { CR } \\
\text { Est. } & \\
\end{array}$ & Kriteria \\
\hline \multirow[t]{2}{*}{$\begin{array}{l}\text { Kesejahteraan } \\
\text { Masyarakat } \\
\text { (Y) }\end{array}$} & $\begin{array}{l}\text { Pelaksanaan } \\
\text { Kebijakan Dana } \\
\text { Desa } \\
\text { (X1) }\end{array}$ & $-0,13$ & $\begin{array}{l}-1,741 \\
(0,082)\end{array}$ & $\begin{array}{l}\text { Prob CR } \\
0,000<\alpha 5 \% \\
\text { H2 Ditolak } \\
\text { (Negatif) }\end{array}$ & $\begin{array}{r}5,548 \\
(0,000)\end{array}$ & $\begin{array}{l}\text { CR }>\text { t tabel df167 } \alpha \\
5 \%=1,654 \\
\text { H3 Diterima }\end{array}$ \\
\hline & $\begin{array}{l}\text { Pemberdayaan } \\
\text { Masyarakat } \\
\text { (X2) }\end{array}$ & 0,96 & $\begin{array}{r}8,206 \\
(0,000)\end{array}$ & $\begin{array}{l}\text { Prob CR } 0,115< \\
\alpha 5 \% \\
\text { H2 Diterima }\end{array}$ & \multicolumn{2}{|c|}{$\begin{array}{l}\text { Rumus Sobel Test (Sobel, 1982): } \\
t / C R=\frac{p 1 p 2}{\operatorname{Sn} 1 n 2}\end{array}$} \\
\hline \multirow[t]{2}{*}{$\begin{array}{l}\text { Pemberdayaa } \\
\text { n Masyarakat } \\
(\mathrm{X} 2)\end{array}$} & $\begin{array}{l}\text { Pelaksanaan } \\
\text { Kebijakaan } \\
\text { Dana Desa } \\
\text { (X1) }\end{array}$ & 0,52 & $\begin{array}{r}7,503 \\
(0,000)\end{array}$ & $\begin{array}{l}\text { Prob CR } \\
0,000<\alpha 5 \% \\
\text { H1 Diterima }\end{array}$ & \multicolumn{2}{|c|}{$\begin{array}{l}\quad S p 1 p 2 \\
\text { Dimana : } \\
S p 1 p 2=\sqrt{p 2^{2} S p 1^{2}+p 1^{2} S p 2^{2}+S p 1^{2} S p 2^{2}}\end{array}$} \\
\hline & & & & & \multicolumn{2}{|c|}{$\begin{array}{l}\text { Keterangan : } \\
\text { p1 = Jalur tidak langsung pertama yang dilalui } \\
\text { p2 = Jalur tidak langsung kedua yang dilalui } \\
\text { Sp1p2 = Standard Estimation p1 dan p2 }\end{array}$} \\
\hline
\end{tabular}

Sumber : Data Diolah, 2020 
Hasil perhitungan Sobel Test :

$S p 1 p 2=\sqrt{p 2^{2} S p 1^{2}+p 1^{2} S p 2^{2}+S p 1^{2} S p 2^{2}}$

$S p 1 p 2=\sqrt{(0.96)^{2}(0.069)^{2}+(0,52)^{2}(0.116)^{2}+(0.069)^{2}(0.116)^{2}}$

Sp1 p $2=\sqrt{0.00439+0.00364+0.0000064}$

$\operatorname{Sp} 1 p 2=\sqrt{0.00809}$

$t / C R=\frac{p 1 p 2}{S p 1 p 2}$

$t / C R=\frac{0.499}{0.0899}$

$t / C R=5.548$

Berdasarkan hasil pengujian hipotesis, dapat dijelaskan bahwa nilai CR/t-hitung pengaruh implementasi kebijakan dana desa terhadap kesejahteraan masyarakat sebesar $1.714<\mathrm{t}$ tabel - 1.654, probabilitas sebesar $0,082>\alpha 5 \%$ berada pada daerah penerimaan H0. Dapat dijustifikasi bahwa pelaksanaan kebijakan dana desa secara langsung memiliki pengaruh yang negatif tidak signifikan terhadap kesejahteraan masyarakat. Dengan demikian hipotesis 1 (H1) yang menyatakan pelaksanaan kebijakan dana desa berpengaurh positif signifikan terhadap kesejahteraan masyarakat tidak dapat diterima atau ditolak.

Berikutnya, nilai $\quad \mathrm{CR} / \mathrm{t}$-hitung pengaruh pemberdayaan masyarakat terhadap kesejahteraan masyarakat sebesar 8,206 > t tabel 1.654, probabilitas sebesar $0,000<\alpha 5 \%$ berada pada daerah penerimaan Ha. Dapat dijustifikasi bahwa pemberdayaan masyarakat secara langsung memiliki pengaruh yang positif dan signifikan terhadap kesejahteraan masyarakat. Dengan demikian hipotesis 2 (H2) yang menyatakan pemberdayaan masyarakat berpengaurh positif dan signifikan terhadap kesejahteraan masyarakat dapat diterima.

Selanjutnya, nilai CR/t-hitung pengaruh pelaksanaan kebijakan dana desa terhadap pemberdayaan masyarakat sebesar $7,503>\mathrm{t}$ tabel 1.654, probabilitas sebesar $0,000>\alpha 5 \%$ berada pada daerah penerimaan Ha. Dapat dijustifikasi bahwa pemberdayaan masyarakat secara langsung memiliki pengaruh yang positif dan signifikan terhadap kesejahteraan masyarakat. Maka hipotesis 3 (H3) yang menyatakan pemberdayaan masyarakat berpengaurh positif dan signifikan terhadap kesejahteraan masyarakat dapat diterima.

Terakhir, nilai CR/t-hitung pengaruh pelaksanaan kebijakan dana desa terhadap kesejahteraan masyarakat melalui pemberdayaan masyarakat sebagai variabel intervening sebesar 5,548 $<\mathrm{t}$ tabel 1.654, berada pada daerah penerimaan Ha. Dapat dijustifikasi bahwa pelaksanaan kebijakan dana desa memiliki pengaruh yang positif dan signifikan terhadap kesejahteraan masyarakat melalui pemberdayaan masyarakat. Dengan demikian hipotesis 4 (H4) yang menyatakan pelaksanaan kebijakan dana desa berpengaurh positif dan signifikan terhadap kesejahteraan masyarakat melalui pemberdayaan masyarakat dapat diterima.

Secara langsung pelaksanaan kebijakan dana desa memiliki rpengaruh yang negatif dan tidak signifikan terhadap kesejahteraan masyarakat. Hal ini ditunjukkan dengan koefisien regresi yang bernilai negatif sebesar -0.13, CR/t-hitung $1.714<\mathrm{t}$ tabel -1.654 dengan probability $0,082<\alpha 5 \%$. Indikator ini menunjukkan 
bahwa pelaksanaan kebijakan dana desa belum berkontribusi didalam meningkatkan kesejahteraan masyarakat. Temuan penelitian ini mendukung penelitian sebelumnya Nurohman dkk., (2019) yang menemukan alokasi dana desa berpengaruh negatif signifikan terhadap kesejahhteraan masyarakat, dan tidak mendukung penelitian Fathony \& Sopian (2019); Oleh (2014) yang menemukan alokasi kebijakan dana desa memiliki pengaruh yang positif dan signifikan terhadap kesejahteraan masyarakat. Temuan ini membuktikan masih terjadinya inkonsitensi hasil penelitian hubungan pelaksanaan kebijakan dana desa terhadap kesejahteraan masyarakat.

Lucyanda (2001) mengatakan diperlukan upaya untuk merekonsiliasi ketidakonsistenan hubungan suatu variable dengan mengidentifikasi faktor-faktor kontekstual antar variabel dengan pendekatan kontijensi yang bertindak sebagai variabel moderating ataupun variabel intervening. Sugionyo (2007) mengatakan untuk menguatkan ataupun melemahkan hubungan antara variabel bebas dengan variabel terikat digunakan variable moderating, sedangkan untuk menjembati tidak ada atau tidak sesuainya hubungan antar variabel dengan teori maupun hasil penelitian terdahulu, digunakan variabel intervening. Baron \& Kenny (1986) mengatakan bahwa analisis regresi model mediating atau intervening akan menghasilkan nilai estimasi prediktor dari intervening dan $\mathrm{X}$ dinamakan jalur $a$ dan intervening terhadap $\mathrm{Y}$ dinamakan jalur $b$. Kedua nilai estimasi predictor ini diharapkan signifikan. Sedangkan prediksi X terhadap Y dinamakan jalur-c', nilainya diharapkan tidak signifikan.

Pasal 1 ayat 2 Peraturan Pemerintah Nomor 60 Tahun 2014 dan Pasal 2 ayat 1 Peraturan Menteri Dalam Negeri No. 113 Tahun 2014 yang menginstruksikan agar dana desa digunakan untuk meningkatkan kesejahteraan masyarakat dengan memberdayakan lembaga kemasyarakatan setempat merupakan ide yang mendasari dikembangkannya pemberdayaan masyarakat sebagai variabel intervening dalam penelitian ini. Merujuk pada pandangan tersebut, secara langsung pemberdayaan masyarakat memiliki pengaruh yang positif dan signifikan terhadap kesejahetraan masyarakat. Hal ini ditunjukkan dengan koefisien estimasi yang bernilai positif, yaitu sebesar 0,96. Nilai CR/t-hitung 8,206 > t tabel 1.654 dengan nilai signifikansi 0,000. Ini membuktikan bahwa pemberdayaan merupakan faktor yang mempengaruhi kesejahteraan masyarakat. Hasil penelitin ini mendukung penelitian sebelumnya yang dilakukan oleh Mahendra (2017) yang menemukan bahwa pemberdayaan masyarakat memiliki pengaruh yang positif dan signifikan terhadap kesejahteraan masyarakat.

Secara langsung, pelaksanaan kebijakan dana desa memiliki pengaruh yang positif dan signifikan pada kesejahteraan masyarakat. Hal ini ditunjukkan dengan dengan koefisien estimasi yang bernilai positif sebesar 0,52, CR/t-hitung 7,503 > ttabel 1.654 dengan probability $0,000<\alpha 5 \%$. Ini membuktikan bahwa pelaksanaan kebijakan dana desa merupakan faktor yang mempengaruhi pemberdayaan masyarakat. 
Hasil penelitin ini mendukung penelitian sebelumnya yang dilakukan oleh Fathony \& Sopian (2019) yang menemukan terdapat pengaruh yang positif dan signifikan alokasi dana desa terhadap pemberdayaan masyarakat.

Pelaksanaan kebijakan dana desa berpengaruh positif dan signifikan terhadap kesejahteraan masyarakat melalui pemberdayaan masyarakat. Hal ini ditunjukkan dengan koefisien estimasi yang bernilai positif sebesar 0,499, CR/t-hitung 5,548> t-tabel 1.654 dengan nilai probability $0,000<\alpha 5 \%$. Ini membuktikan bahwa hubungan yang sesungguhnya antara pelaksanaan kebijakan dana desa dengan kesejahteraan masyarakat, bukanlah hubungan langsung, melainkan melalui pemberdayaan masyarakat sebagai variabel intervening. Dengan pemberdayaan masyarakat, kebijakan dana desa diestimasi dapat meningkatkan kesejahteraan masyarakat. Hal ini sesuai dengan arahan Pasal 1 ayat 2 Peraturan Pemerintah Nomor 60 Tahun 2014 serta Pasal 2 ayat 1 Peraturan Menteri Dalam Negeri No. 113 Tahun 2014 yang mengintruksikan agar dana desa digunakan sebesar-besarnya untuk kesejahteraan masyarakat dengan memberdayakan lembaga kemasyarakatan setempat.

\section{SIMPULAN DAN SARAN}

Berdasarkarkan hasil analisis dan pembahasan yang dilakukan dalam penelitian ini, ditarik kesimpulan : 1) Secara langsung pelaksanaan kebijakan dana desa memiliki pengaruh yang negatif dan tidak signifikan terhadap kesejahteraan masyarakat desa di Kecamatan Siantar Narumonda Kabupaten Toba. Hal tersebut menunjukkan pelaksanaan kebijakan dana desa di Kecamatan Siantar Narumonda Kabupaten Toba belum efektif didalam meningkatkan kesejahteraan masyarakatnya. 2) Secara langsung, pemberdayaan masyarakat memiliki pengaruh yang positif dan signifikan terhadap kesejahteraan masyarakat desa di Kecamatan Narumonda Kabupaten Toba. Hal tersebut juga menunjukkan semakin meningkat pemberdayaan masyarakat, maka kesejahteraan masyarakat Desa di Kecamatan Siantar Narumonda juga akan meningkat. 3) Secara langsung, pelaksanaan kebijakan dana desa memiliki pengaruh yang positif dan signifikan terhadap pemberdayaan masyarakat desa di Kecamatan Narumonda Kabupaten Toba. Hal tersebut juga menunjukkan semakin meningkat pelaksanan kebijakan dana desa (penyerapan anggaran dana desa), maka pemberdayaan masyarakat di Kecamatan Siantar Narumonda juga akan meningkat. 4) Pelaksanaan kebijakan dana desa memiliki pengaruh yang positif dan signifikan terhadap kesejahteraan masyarakat desa di Kecamatan Siantar Narumonda melalui pemberdayaan masyarakat sebagai variabel intervening. Hal tersebut menunjukkan kesejahteraan masyarakat akan meningkat bila kebijakan dana desa dilaksanakan dengan memberdayakan masyarakat seutuhnya. Semakin diberdayakan masyarakat dalam pelaksanakan kebijikan dana desa, maka kesejahteraan masyarakat juga akan meningkat. 
Berdasarkan kesimpulan yang dihasilkan dalam penelitian ini, selanjutnya direkomendasikan saran agar Pemerintah Desa menjaga dana desa yang dialokasikan untuk tujuan pemberdayaan masyarakat lebih tepat guna dan tepat sasaran dengan melakukan: pengembangan sosial, pengembangan ekonomi pengembangan politik, pengembangan budaya pengembangan lingkungan dan pengembangan personal/spritual, seperti : membangun sentra-sentra pemasaran UMKM, membangun BUMdes, membangun sarana dan prasarana kesehatan, melakukan promosi dan penyuluhan program kesehatan masyarakat, merenovasi atau membangun sarana dan prasarana pendidikan, menggalakkan kegiatan-kegiatan PKK dan karang taruna, mencegah masuknya narkoba, pornografi, hingga gerakan radikal yang mengatasnamakan agama. Kelemahan penelitian ini terletak pada analisis data yang hanya didasarkan pada penggunaan data yang bersumber survei kuesioner. Oleh karena itu, hendaknya penggunaan data sekunder sebagai pembanding data yang bersumber survei kuesioner juga dianalisis, sehingga penelitian yang dihasilkan dapat men-generalisir kondisi lapangan yang sesungguhnya.

\section{REFERENSI}

Arsyad, L. (2010). Ekonomi Pembangunan. Edisi Keempat. Yogyakarta: STIE YKPN.

Badan Pusat Statistik. (2016). Booklet Indeks Pembangunan Manusia Metode Baru. Jakarta.

Badan Pusat Statistik Kecamatan Siantar Narumonda (2019), Kecamatan Siantar Narumonda Dalam Angka 2018.

Baron, R. M., \& Kenny, D. A. (1986). The moderatormediator variable distinction in social psychological research: Conceptual, strategic, and statistical considerations. Journal of Personality and Social Psychology, 51(6), 1173-1182. https://doi.org/10.1037//00223514.51.6.1173

Fathony, A. A., \& Sopian, A. (2019). Pengaruh Alokasi Dana Desa Terhadap Pemberdayaan Masyarakat Dan Peningkatan Kesejahteraan Masyarakat Di Desa Langonsari Kecamatan Pameungpeuk Kabupaten Bandung. Jurnal Ilmiah Akuntansi, 10(3), 41-57.

Ferdinand, A. (2006). Metode Penelitian Manajemen: Pedoman Penelitian untuk Skripsi, Tesis, dan Disertasi Imu Manajemen. Semarang : Universitas Diponegoro.

Ghozali, I. (2011). Aplikasi Analisis Multivariate dengan Program IBM SPSS21 Update PLS Regresi, Edisi Ketujuh, Semarang : Badan Penerbit Universitas Diponegoro.

Hair, J. F., Jr., et. al. (1995). Multivariate Data Analysis with Reading, 4rd Edition, New Jersey : Prentice-Hall International Inc

Ife, J., \& Frank, T.. (2008). Community Development : Alternatif. Pengembangan Masyarakat di Era Globalisasi, Yogyakarta : Pustaka

Loehlin, J.C. (1998). Latent Variable Models: An Introduction to Factor, Path, and Structural Analysis. New Jersey : Lawrence Erlbaum Associates, Inc

Lucyanda, J. (2001). Hubungan antara anggaran partisipatif dengan kinerja manajerial: peran locus of control sebagai variabel moderating dan motivasi sebagai variabel intervening. Tesis. Program Pascasarjana. Yogyakarta : Universitas Gajah Mada.

Mahendra, B. P. (2017). Analisis Pengaruh Program Nasional Pemberdayaan Masyarakat Mandiri Perkotaan (Pnpm Mp) Terhadap Produktifitas Kerja Dan Kesejahteraan Masyarakat. International Journal of Social Science and Business, $1(1), \quad 1-13$. https://doi.org/10.23887/ijssb.v1i1.10165

Maulana, 2017. Pengelolaan Alokasi Dana Desa Dalam Meningkatkan Pemberdayaan Masyarakat di Desa Miau Baru Kecamatan Kongbeng Kabupaten Kutai Timur. Skripsi. Kalimanta Timur : Fakultas Ilmu Sosial dan Politik, Unviersitas Mulawarman

Noor, J. (2011). Metodologi Penelitian, Jakarta: Kencana Prenada Media Grup.

Nugroho, R. (2014). Public Policy: Teori, Manajemen, Dinamika, Analisis, Konvergensi dan Kimia Kebijakan. Jakarta: Elex Media Komputindo. 
Nurohman, Y. A., Qurniawati, R. S., \& Hasyim, F. (2019). Dana Desa Dalam Peningkatan Kesejahteraan Masyarakat Pada Desa Wisata Menggoro. Magisma: Jurnal Ilmiah Ekonomi Dan Bisnis, 7(1), 35-43. https://doi.org/10.35829/magisma.v7i1.38

Oleh, H. F., (2014). Pelaksanaan Kebijakan Alokasi Dana Desa (ADD) dalam Memberdayakan Masyarakat Desa di Desa Cerme, Kecamatan Grogol, Kabupaten Kediri. Jurnal Kebijakan dan Manajemen Publik, 2 (1) : 1 -8

Peraturan Pemerintah Republik Indonesia Nomor 60 Tahun 2014 tentang Dana Desa yang Bersumber Dari Anggaran Pendapatan Dan Belanja. Negara.

Peraturan Menteri Dalam Negeri Republik Indonesia Nomor 113 Tahun 2014 tentang Pedoman Pengelolaan Keuangan Desa.

Peraturan Pemerintah Nomor 8 Tahun 2016 Tentang Dana Desa yang Bersumber dari Anggaran Pendapatan dan Belanja Negara

Ramdhani, A., \& Ramdhani, M. A. (2017). Konsep Umum Pelaksanaan Kebijakan Publik. Jurnal Publik, 11(1) : 1-12.

Subarsono, A. G, (2005). Analisis Kebijakan Publik Konsep, Teori dan Aplikasi. Yogyakarta : Pustaka Pelajar.

Sugiyono. (2007). Metode penelitian kuantitatif kualitatif dan R\&D. Bandung : Alfabeta.

Undang-Undang Nomor 6 Tahun 2014 tentang Desa

Undang - Undang No 11 Tahun 2009 tentang Kesejahteraan Sosial.

Waluyo, M. (2011). Panduan dan Aplikasi Struktural Equation Modelling untuk Aplikasi Model dalam Penelitian Teknik Industri, Psikologi, Sosial dan Manajemen, Jakarta: PT Indeks. 